\title{
Influence of Gender on Outcome of Severe Sepsis
}

\author{
C. Adrie, E. Azoulay, and J.-F. Timsit, for the OUTCOMEREA Study Group
}

\section{Introduction}

Whether gender influences the outcome of severe sepsis remains a matter of debate. Because many confounding variables may affect observed associations between gender and mortality, high-quality statistical analyses are essential to carefully adjust the two groups of patients. About $55 \%$ to $65 \%$ of patients with sepsis have chronic co-morbidities associated with immune dysfunction (e.g., chronic renal failure, diabetes mellitus, human immunodeficiency virus [HIV] infection, and alcohol abuse), which increase the susceptibility to sepsis [1]. Genetic polymorphisms that affect the susceptibility to infection and/or the severity of the systemic response to infection [2] may lead to variability among individuals and between males and females [3]. Access to healthcare, another determinant of the incidence and outcome of sepsis, varies according to age, ethnic group, and gender, although a recent study conducted in the USA found only relatively small quality-of-care differences between males and females or across income groups compared to the gap for each subgroup between observed and desirable quality of health care [4]. Here, we review the data on the existence of, and reasons for, associations between gender and outcome of severe sepsis (Fig. 1).

Fig. 1. Diagram showing the main factors that may lead to discrepancies in data from clinical studies into the influence of gender on survival of patients with severe sepsis. Confounders include differences in age, case-mix, nature of the injury preceding sepsis development (e.g., trauma, hemorrhage, or burns), infection source, co-morbidities, and menopausal status. In addition, level of care may differ

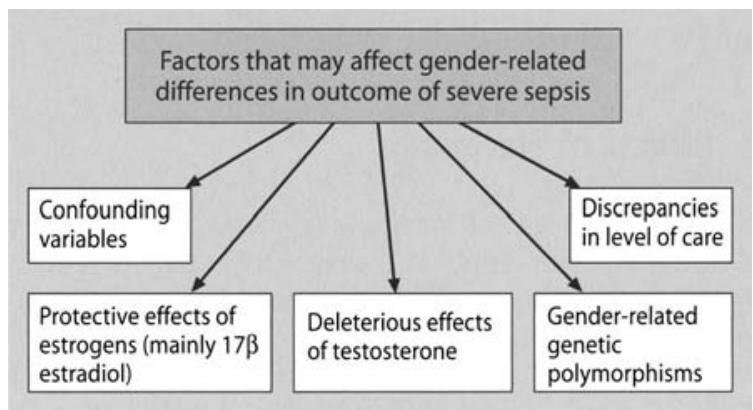
between men and women. Finally, gender-related genetic polymorphisms that affect innate immunity have been identified. Estrogen (17 $\beta$ estradiol) may exert beneficial effects and testosterone deleterious effects. 


\section{Epidemiological Data}

Severe sepsis remains among the leading causes of death in western Europe and North America [5,6]. Mortality rates in patients with severe sepsis range from $20 \%$ to $50 \%$ depending on the nature and number of organ dysfunctions. The incidence of sepsis has increased over the last two decades [5], and disparities have been identified across ethnic groups and between genders. In the US, the incidence of sepsis was lower in females than in males for all sources of infection except the genitourinary tract. After adjustment for gender, men were more likely to have sepsis than women in every year of a 22-year study, the mean annual risk being 1.28 [5]. Similarly, other studies showed that men had a higher risk of infection [6] and were more likely to develop sepsis after surgery or trauma $[7,8]$. Acute lung injury (ALI) was more common, and was associated with worse outcomes, in men compared to women $[7,9-11]$. In a study of 545 patients older than 15 years who were admitted for trauma, male gender was associated with a dramatically increased incidence of major infection in all age groups, and the difference between genders was greatest for moderately severe trauma (Injury Severity Score 16-25) [8]. The lower incidence in women of pneumonia, sepsis and multiple organ failure after trauma has been confirmed in other clinical studies $[8,12-14]$. Thus, there is general agreement that the incidence of sepsis is higher in males than in females. However, the influence of gender on the outcome of established sepsis is far more difficult to assess.

Assessment of the influence of gender on the outcome of established sepsis in clinical studies has produced conflicting results, perhaps as a result of differences in age, case-mix, nature of the injury (e.g., trauma, hemorrhage, or burns), infection sources, co-morbidities, and menopausal status $[7,8,11,13,15-18]$. For instance, in surgical units, survival has been reported to be better in women [11], better in men [18], and independent of gender [7]. Although differences in sample size and casemix probably contributed to these discrepancies, the main factor may be imperfect matching of males and females. By using a propensity score computed for patients with severe sepsis included in the Outcomerea database ${ }^{\circledR}$, we were able to adjust carefully for confounding variables. We found that hospital mortality was significantly lower in women [19]. This difference was present in older patients but not in pre-menopausal patients $(<50$ years of age).

\section{Effects of Hormones}

Sex hormones [20] or gender-related gene polymorphisms [3, 21] may protect women against sepsis and death from sepsis. Differences in hormone profiles have been widely suggested as the cause of gender-based differences in the incidence and outcome of sepsis.

Experimental evidence suggested a protective role for female sex hormones [20]. Female mice tolerate polymicrobial sepsis better than do male mice [22]. In "twohit" models, animals are exposed to hemorrhagic shock or trauma, which is expected to alter or suppress the response to a second insult, such as sepsis [23-25]. In murine two-hit models with sepsis as the second insult, survival was improved in males after testosterone receptor blockade [26] or administration of the inactive testosterone metabolite, dehydroepiandrosterone [27]. Suggested explanations for these findings include better preservation of innate immunity [28], the endothelium [29] or the gut barrier via improved splanchnic perfusion [25]. Cristafaro et al. [30] 
reported that oral administration of WAY -202196 , a selective estrogen-receptor- $\beta$ agonist, preserved gastrointestinal barrier function and improved outcomes in three different models of murine sepsis (Listeria infection, Pseudomonas aeruginosa infection in neutropenic rats, and cecal ligation and puncture in mice).

Thus, estrogens may exert beneficial effects and testosterone detrimental effects in experimental sepsis. However, clinical studies have produced conflicting results. And in a more recent study, mortality in elderly patients with severe sepsis was independent from gender but correlated with higher serum levels of $17 \beta$-estradiol and progesterone in males and of $17 \beta$-estradiol and testosterone in females [31].

The most extensively studied estrogen is $17 \beta$-estradiol, which is the most active. It suppresses major histocompatibility complex II (MHC II) proteins in a tissue-specific manner [32-34] and acts centrally on the immune system by helping to activate $5 \mathrm{HT}_{2 \mathrm{~A}}$ receptors in the thymus [35]. Estrogen treatment also indirectly suppresses MHC II protein expression via serotonin production. Specifically, increased $5 \mathrm{HT}_{2 \mathrm{~A}}$ activity causes decreased $\mathrm{MHC}$ II production and decreased selection against self-reactive helper $\mathrm{T}$ cells (Th1) $[36,37]$. Interplay between estrogen and serotonin has also been demonstrated in the vascular system, one important result being alteration of coagulation [38], which is also closely linked to inflammation [39]. Other estrogen effects that protect against acute injury include p38 mitogen-activated protein kinase (MAPK) activation, antioxidant effects, increased nitric oxide (NO) production, modulation of calcium influx and release, activation of KATP channels, and decreased apoptosis [20].

The above-described potential mechanisms of gender-related differences in responses to sepsis would lead to expect better survival in pre-menopausal women than in men. However, this was not usually the case in clinical studies. In post-menopausal women, estrogens are produced outside the ovaries, presumably within the adrenal cortex, although other sources such as $\mathrm{T}$ cells, macrophages, and fat tissue may contribute to the high sex-steroid levels observed in severe sepsis. The metabolism of the adrenal hormone, dehydroepiandrosterone, is a major determinant of sex-steroid status in post-menopausal women. Dehydroepiandrosterone is a very weak androgen but can be converted either to more potent androgens or to estrogens by peripheral tissue enzymes (5-reductase for conversion to dihydrotestosterone and aromatase for conversion to 17-estradiol) [40]. The higher body mass index observed in women than men may lead to better protection as a result of greater aromatase activity in fat tissue. Both obesity and advancing age are known to increase aromatase activity [40]. In a recent study [31], survival in elderly patients with severe infection was similar in men and women but varied with the sex-steroid profile. The absence of a gender difference may be ascribable to the small sample size and to the inclusion of patients with sepsis with or without organ dysfunction [31]. Furthermore, confounding factors were not correctly taken into account [31]. Moreover, sex hormone profiles during severe sepsis may fail to reflect baseline hormone production, since severe sepsis is often preceded by several days of systemic inflammation, a process known to decrease testosterone levels [41-43] and to increase $17 \beta$-estradiol synthesis via an increase in aromatase activity $[44,45]$.

Testosterone may be deleterious in patients with sepsis. Testosterone exerts immunosuppressive effects [46], chiefly through activation and repression of transcription [47]. Testosterone administration causes death in female mice with Plasmodium chaboudi blood-stage malaria, which is normally self-limited [48]. Interestingly, the detrimental effects of testosterone occurred in the liver rather than the spleen [48]. Testosterone administration altered the activity of the reticular endothe- 
lial system in the liver, dramatically suppressing both the malaria-protective gene encoding plasminogen activator inhibitor (PAI-1) and the gene encoding hydroxysteroid sulfotransferase (STA2). Moreover, testosterone increased p38 MAPK activation, upregulated adrenergic receptors and calcium-channel expression, and induced apoptosis (for a review see [20]). These effects were mainly observed in acute myocardial inflammatory response to acute injury, and were also present, at least in part, in a trauma-hemorrhage mouse model [49]. Nevertheless, whether these mechanisms are operative in severe sepsis remains to be determined.

In pre-menopausal women, 17-estradiol produced by the ovaries is the chief circulating estrogen. Serum estradiol concentrations are low in prepubertal girls and increase at menarche. In women, they range from about $100 \mathrm{pg} / \mathrm{ml}(367 \mathrm{pmol} / \mathrm{l})$ in the follicular phase to about $600 \mathrm{pg} / \mathrm{ml}(2200 \mathrm{pmol} / \mathrm{l})$ at ovulation. Serum estradiol may reach nearly $20,000 \mathrm{pg} / \mathrm{ml}(70,000 \mathrm{pmol} / \mathrm{l})$ during pregnancy. After the menopause, serum estradiol concentrations fall to values similar to or lower than those in same-age men ( 5 to $20 \mathrm{pg} / \mathrm{ml} ; 18$ to $74 \mathrm{pmol} / \mathrm{l}$ ). The protective effect of estrogen on the cardiovascular system has been widely studied [50], and many of the pathophysiological mechanisms underlying atherosclerosis are also involved in the inflammatory process that characterizes severe sepsis. However, in our study mortality was lower in older post-menopausal women [19]. Moreover, mortality is also higher in male children [16], who have extremely low levels of testosterone and other sex hormones. These data suggest a role for other factors, such as gender-related genetic polymorphisms.

\section{Gender-related Genetic Polymorphisms}

Gender-related genetic polymorphisms may contribute to the higher mortality from sepsis in males compared to females. Data from a case-control study by Hubacek et al. [21] suggest that common polymorphisms in the gene for lipopolysaccharide binding protein (LBP) may increase both the risk of sepsis and the risk of death from sepsis in men, but not in women. TNF $\beta$ Ncol restriction fragment length polymorphism affected the amino acid at position 26 of the TNF $\beta$ sequence, which was aspariginase with one allele (TNFB1) and threonine with the other (TNFB2) [51]. The genotype distribution of patients homozygous for TNFB1 and heterozygous or homozygous for TNFB2 was comparable between men and women with severe sepsis in a surgical ICU [3]. In women, no difference in survival rate was found between the different genotypes, whereas mortality was significantly higher in men homozygous for TNFB2 than in men with the other genotypes. The survival rate was higher in women overall but was not significantly different between men and women with the TNB2/B2 genotype [3]. The IL-1 receptor-associated kinase (IRAK-1) variant haplotype is functionally significant in patients with sepsis, being associated with increased nuclear translocation of nuclear factor- $\mathrm{KB}(\mathrm{NF}-\mathrm{KB})$, greater severity of organ dysfunction, and higher mortality [52]. Because the IRAK-1 haplotypes are located on the $\mathrm{X}$ chromosome (at position q28), a larger percentage of men than women are functionally homozygous. Therefore, men are more likely than women to exhibit functional effects of the variant IRAK-1 haplotype, which may lead to an increased risk of sepsis-associated multiple organ dysfunction and death. There was no significant increase in adverse outcomes in heterozygous females [52], indicating that the effects of the IRAK-1 haplotype are not dominant. 


\section{Levels of Care}

Studies in the USA showed that patients received about half the recommended level of healthcare, with remarkably little variation across geographic regions $[53,54]$. However, differences in quality of care have been found among population subgroups. Differences in the level of care may lead to differences in survival between men and women. In one study, for instance, women received better care than men overall; however, higher quality scores for preventive and chronic care masked lower scores for acute care [4]. Similarly, poorer acute care in women has been reported for cardiovascular disease [55]. In several studies, women were less likely than men to undergo intensive evaluation and invasive treatment for cardiovascular disease [56-58]. A large cohort study conducted in Austria in critically ill patients [59] showed greater use of invasive procedures in men compared to women, in all age groups. After adjustment for age, men were more likely than women to receive multiple invasive procedures, even in the youngest age groups. Although disease severity was greater in women, survival was not significantly different, suggesting either an inappropriately high level of care in men or a better potential for survival in women masked by an inappropriately low level of care. However, resource use according to gender may vary across healthcare systems, indicating a need for studies in countries that use different systems. In addition, this study [59] enrolled all ICU patients rather than only those with severe sepsis. In our study, the Nine Equivalents of Nursing Manpower Score (NEMS-9) was similar in men and women, suggesting level of care was identical in this particular subgroup of patients with severe sepsis in a French ICU database (Outcomerea Database) [19].

\section{Conclusion}

Men are at greater risk for sepsis than are women. Numerous experimental data suggest better outcomes in females with severe sepsis, compared to males. Nevertheless, clinical data in humans are conflicting. Further work is needed to determine the influence of gender on outcomes of severe sepsis. Studies must pay careful attention to matching the males and females for the many potential confounding variables.

\section{References}

1. Esper AM, Moss M, Lewis CA, Nisbet R, Mannino DM, Martin GS (2006) The role of infection and comorbidity: Factors that influence disparities in sepsis. Crit Care Med 34:2576-2582

2. Arcaroli J, Fessler MB, Abraham E (2005) Genetic polymorphisms and sepsis. Shock $24: 300-312$

3. Schroder J, Kahlke V, Book M, Stuber F (2000) Gender differences in sepsis: genetically determined? Shock 14:307-310

4. Asch SM, Kerr EA, Keesey J, et al (2006) Who is at greatest risk for receiving poor-quality health care? N Engl J Med 354:1147-1156

5. Martin GS, Mannino DM, Eaton S, Moss M (2003) The epidemiology of sepsis in the United States from 1979 through 2000. N Engl J Med 348:1546-1554

6. Adrie C, Alberti C, Chaix-Couturier C, et al (2005) Epidemiology and economic evaluation of severe sepsis in France: age, severity, infection site, and place of acquisition (community, hospital, or intensive care unit) as determinants of workload and cost. J Crit Care 20:46-58

7. Wichmann MW, Inthorn D, Andress HJ, Schildberg FW (2000) Incidence and mortality of severe sepsis in surgical intensive care patients: the influence of patient gender on disease process and outcome. Intensive Care Med 26:167-172 
8. Offner PJ, Moore EE, Biffl WL (1999) Male gender is a risk factor for major infections after surgery. Arch Surg 134:935-938

9. Moss M, Mannino DM (2002) Race and gender differences in acute respiratory distress syndrome deaths in the United States: an analysis of multiple-cause mortality data (1979-1996). Crit Care Med 30:1679-1685

10. Angus DC, Linde-Zwirble WT, Lidicker J, Clermont G, Carcillo J, and Pinsky MR (2001) Epidemiology of severe sepsis in the United States: analysis of incidence, outcome, and associated costs of care. Crit Care Med 29:1303-1310.

11. Schroder J, Kahlke V, Staubach KH, Zabel P, and Stuber F (1998) Gender differences in human sepsis. Arch Surg 133:1200-1205

12. Oberholzer A, Keel M, Zellweger R, Steckholzer U, Trentz O, and Ertel W (2000) Incidence of septic complications and multiple organ failure in severely injured patients is sex specific. $J$ Trauma 48:932-937

13. Mostafa G, Huynh T, Sing RF, Miles WS, Norton HJ, and Thomason MH (2002) Genderrelated outcomes in trauma. J Trauma 53:430-434

14. Gannon CJ, Pasquale M, Tracy JK, McCarter RJ, and Napolitano LM (2004) Male gender is associated with increased risk for postinjury pneumonia. Shock 21:410-414

15. Crabtree TD, Pelletier SJ, Gleason TG, Pruett TL, Sawyer RG (1999) Gender-dependent differences in outcome after the treatment of infection in hospitalized patients. JAMA 282:21432148

16. Bindl L, Buderus S, Dahlem P, et al (2003) Gender-based differences in children with sepsis and ARDS: the ESPNIC ARDS Database Group. Intensive Care Med 29:1770-1773

17. George RL, McGwin G Jr, Schwacha MG, et al (2005) The association between sex and mortality among burn patients as modified by age. J Burn Care Rehabil 26:416-421

18. Eachempati SR, Hydo L, Barie PS (1999) Gender-based differences in outcome in patients with sepsis. Arch Surg 134:1342-1347

19. Adrie C, Francais A, Garrouste-Orgeas $M$, et al (2006) Sex gender influences the outcome of severe sepsis. Intensive Care Med 32:S0309 (abst)

20. Kher A, Wang M, Tsai BM, et al (2005) Sex differences in the myocardial inflammatory response to acute injury. Shock 23:1-10

21. Hubacek JA, Stuber F, Frohlich D, et al (2001) Gene variants of the bactericidal/permeability increasing protein and lipopolysaccharide binding protein in sepsis patients: gender-specific genetic predisposition to sepsis. Crit Care Med 29:557-561

22. Zellweger R, Wichmann MW, Ayala A, Stein S, DeMaso CM, Chaudry IH (1997) Females in proestrus state maintain splenic immune functions and tolerate sepsis better than males. Crit Care Med 25:106-110

23. Knoferl MW, Angele MK, Catania RA, Diodato MD, Bland KI, Chaudry IH (2003) Immunomodulatory effects of dehydroepiandrosterone in proestrus female mice after trauma-hemorrhage. J Appl Physiol 95:529-535

24. Diodato MD, Knoferl MW, Schwacha MG, Bland KI, Chaudry IH (2001) Gender differences in the inflammatory response and survival following haemorrhage and subsequent sepsis. Cytokine 14:162-169

25. Kuebler JF, Jarrar D, Toth B, et al (2002) Estradiol administration improves splanchnic perfusion following trauma-hemorrhage and sepsis. Arch Surg 137:74-79

26. Angele MK, Wichmann MW, Ayala A, Cioffi WG, Chaudry IH (1997) Testosterone receptor blockade after hemorrhage in males. Restoration of the depressed immune functions and improved survival following subsequent sepsis. Arch Surg 132:1207-1214

27. Angele MK, Catania RA, Ayala A, Cioffi WG, Bland KI, Chaudry IH (1998) Dehydroepiandrosterone: an inexpensive steroid hormone that decreases the mortality due to sepsis following trauma-induced hemorrhage. Arch Surg 133:1281-1288

28. Imahara SD, Jelacic S, Junker CE, O'Keefe GE (2005) The influence of gender on human innate immunity. Surgery 138:275-282

29. Tsai BM, Wang M, Pitcher JM, Kher A, Brown JW, Meldrum DR (2005) Endothelium-dependent pulmonary artery vasorelaxation is dysfunctional in males but not females after acute lung injury. Surgery 138:78-84

30. Cristofaro PA, Opal SM, Palardy JE, et al (2006) WAY-202196, a selective estrogen receptor-beta agonist, protects against death in experimental septic shock. Crit Care Med 34:2188-2193. 
31. Angstwurm MW, Gaertner R, Schopohl J (2005) Outcome in elderly patients with severe infection is influenced by sex hormones but not gender. Crit Care Med 33:2786-2793

32. Nalbandian G, Kovats $S$ (2005) Understanding sex biases in immunity: effects of estrogen on the differentiation and function of antigen-presenting cells. Immunol Res 31:91-106

33. Adamski J, Ma Z, Nozell S, Benveniste EN (2004) 17beta-Estradiol inhibits class II major histocompatibility complex (MHC) expression: influence on histone modifications and cbp recruitment to the class II MHC promoter. Mol Endocrinol 18:1963-1974

34. Adamski J, Benveniste EN (2005) 17beta-estradiol activation of the c-Jun N-terminal kinase pathway leads to down-regulation of class II major histocompatibility complex expression. Mol Endocrinol 19:113-124

35. Pellegrino TC and Bayer BM (2002) Role of central 5-HT(2) receptors in fluoxetine-induced decreases in $\mathrm{T}$ lymphocyte activity. Brain Behav Immun 16:87-103

36. Narita J, Miyaji C, Watanabe H, et al (1998) Differentiation of forbidden $\mathrm{T}$ cell clones and granulocytes in the parenchymal space of the liver in mice treated with estrogen. Cell Immunol $185: 1-13$

37. Cloez-Tayarani 1, Petit-Bertron AF, Venters HD, Cavaillon JM (2003) Differential effect of serotonin on cytokine production in lipopolysaccharide-stimulated human peripheral blood mononuclear cells: involvement of 5-hydroxytryptamine2A receptors. Int Immunol 15:233240

38. Rybaczyk LA, Bashaw MJ, Pathak DR, Moody SM, Gilders RM, Holzschu DL (2005) An overlooked connection: serotonergic mediation of estrogen-related physiology and pathology. BMC Womens Health 5:1-10

39. Esmon CT (2003) Coagulation and inflammation. J Endotoxin Res 9:192-198

40. Federman DD (2006) The biology of human sex differences. N Engl J Med 354:1507-1514

41. Sharma AC, Bosmann HB, Motew SJ, Hales KH, Hales DB, Ferguson JL (1996) Steroid hormone alterations following induction of chronic intraperitoneal sepsis in male rats. Shock $6: 150-154$

42. Sam AD, 2nd, Sharma AC, Lee LY, et al (1999) Sepsis produces depression of testosterone and steroidogenic acute regulatory (StAR) protein. Shock 11:298-301

43. Mechanick JI, Nierman DM (2006) Gonadal steroids in critical illness. Crit Care Clin 22: $87-103$

44. Zhao Y, Nichols JE, Valdez R, Mendelson CR, Simpson ER (1996) Tumor necrosis factor-alpha stimulates aromatase gene expression in human adipose stromal cells through use of an activating protein-1 binding site upstream of promoter 1.4. Mol Endocrinol 10:1350-1357

45. Macdiarmid F, Wang D, Duncan LJ, Purohit A, Ghilchick MW, Reed MJ (1994) Stimulation of aromatase activity in breast fibroblasts by tumor necrosis factor alpha. Mol Cell Endocrinol 106:17-21

46. Seli E, Arici A (2002) Sex steroids and the immune system. Immunol Allergy Clin N Am 22:407-408

47. Lee HJ, Chang C (2003) Recent advances in androgen receptor action. Cell Mol Life Sci $60: 1613-22$

48. Krucken J, Dkhil MA, Braun JV, et al (2005) Testosterone suppresses protective responses of the liver to blood-stage malaria. Infect Immun 73:436-43

49. Angele MK, Nitsch S, Knoferl MW, et al (2003) Sex-specific p38 MAP kinase activation following trauma-hemorrhage: involvement of testosterone and estradiol. Am J Physiol Endocrinol Metab 285:E189-196

50. Mendelsohn ME, Karas RH (1999) The protective effects of estrogen on the cardiovascular system. N Engl J Med 340:1801-1811

51. Messer G, Spengler U, Jung MC, et al (1991) Polymorphic structure of the tumor necrosis factor (TNF) locus: an NcoI polymorphism in the first intron of the human TNF-beta gene correlates with a variant amino acid in position 26 and a reduced level of TNF-beta production. J Exp Med 173:209-219

52. Arcaroli J, Silva E, Maloney JP, et al (2006) Variant IRAK-1 haplotype is associated with increased nuclear factor-kappaB activation and worse outcomes in sepsis. Am J Respir Crit Care Med 173:1335-1341

53. Kerr EA, McGlynn EA, Adams J, Keesey J, Asch SM (2004) Profiling the quality of care in twelve communities: results from the CQI study. Health Aff (Millwood) 23:247-256 
54. McGlynn EA, Asch SM, Adams J, et al (2003) The quality of health care delivered to adults in the United States. N Engl J Med 348:2635-2645

55. Redberg RF (2005) Gender, race, and cardiac care: why the differences? J Am Coll Cardiol $46: 1852-1854$

56. Jaglal SB, Goel V, Naylor CD (1994) Sex differences in the use of invasive coronary procedures in Ontario. Can J Cardiol 10:239-244

57. Ayanian JZ, Epstein AM (1991) Differences in the use of procedures between women and men hospitalized for coronary heart disease. N Engl J Med 325:221-225

58. Vaccarino V, Rathore SS, Wenger NK, et al (2005) Sex and racial differences in the management of acute myocardial infarction, 1994 through 2002. $\mathrm{N}$ Engl J Med 353:671-682

59. Valentin A, Jordan B, Lang T, Hiesmayr M, Metnitz PG (2003) Gender-related differences in intensive care: a multiple-center cohort study of therapeutic interventions and outcome in critically ill patients. Crit Care Med 31:1901-1907 